\title{
A large-area blackbody for in-flight calibration of an infrared interferometer deployed on board a long-duration balloon for stratospheric research
}

\author{
Friedhelm Olschewski ${ }^{1}$, Christian Monte $^{2}$, Albert Adibekyan ${ }^{2}$, Max Reiniger $^{2}$, Berndt Gutschwager $^{2}$, \\ Joerg Hollandt ${ }^{2}$, and Ralf Koppmann ${ }^{1}$ \\ ${ }^{1}$ Institute for Atmospheric and Environmental Research at the University of Wuppertal, 42097 Wuppertal, Germany \\ ${ }^{2}$ Physikalisch-Technische Bundesanstalt, 10587 Berlin, Germany
}

Correspondence: Friedhelm Olschewski (olsch@uni-wuppertal.de)

Received: 20 November 2017 - Discussion started: 13 March 2018

Revised: 9 July 2018 - Accepted: 24 July 2018 - Published: 14 August 2018

\begin{abstract}
The deployment of the imaging Fourier Transform Spectrometer GLORIA (Gimballed Limb Observer for Radiance Imaging of the Atmosphere) on board a long-duration balloon for stratospheric research requires a blackbody for in-flight calibration in order to provide traceability to the International Temperature Scale (ITS-90) to ensure comparability with the results of other experiments and over time. GLORIA, which has been deployed onboard various research aircraft such as the Russian M55 Geophysica or the German HALO in the past, shall also be used for detailed atmospheric measurements in the stratosphere up to $40 \mathrm{~km}$ altitude. The instrument uses a two-dimensional detector array and an imaging optics with a large aperture diameter of $36 \mathrm{~mm}$ and an opening angle of $4.07^{\circ} \times 4.07^{\circ}$ for infrared limb observations. To overfill the field of view (FOV) of the instrument, a large-area blackbody radiation sources $(125 \mathrm{~mm} \times 125 \mathrm{~mm})$ is required for in-flight calibration.

In order to meet the requirements regarding the scientific goals of the GLORIA missions, the radiance temperature of the blackbody calibration source has to be determined to better than $100 \mathrm{mK}$ and the spatial temperature uniformity shall be better than $150 \mathrm{mK}$. As electrical resources on board a stratospheric balloon are very limited, the latent heat of the phase change of a eutectic material is utilized for temperature stabilization of the calibration source, such that the blackbody has a constant temperature of about $-32^{\circ} \mathrm{C}$ corresponding to a typical temperature observed in the stratosphere.

The Institute for Atmospheric and Environmental Research at the University of Wuppertal designed and manu-
\end{abstract}

factured a prototype of the large-area blackbody for in-flight calibration of an infrared interferometer deployed on board a long-duration balloon for stratospheric research. This newly developed calibration source was tested under lab conditions as well as in a climatic and environmental test chamber in order to verify its performance especially under flight conditions. At the PTB (Physikalisch-Technische Bundesanstalt), the German national metrology institute, the spatial radiance distribution of the blackbody was determined and traceability to the International Temperature Scale (ITS-90) has been assured. In this paper the design and performance of the balloon-borne blackbody (BBB) is presented.

\section{Introduction}

The Gimballed Limb Observer for Radiance Imaging of the Atmosphere (GLORIA) is an imaging Fourier Transform Spectrometer (FTS) developed for trace gas measurements in the atmosphere. GLORIA utilizes a two-dimensional MCT detector array with a large aperture optical system for detailed infrared limb observations (Riese et al., 2014; FriedlVallon et al., 2006). In the past, GLORIA participated in various international research campaigns (Friedl-Vallon, 2016) (e.g., TACTS 2012, Kaufmann et al., 2015, POLSTRACC 2015, Krisch et al., 2017, STRATO-CLIM 2016, Johansson et al., 2017, WISE 2017) deployed on board the research aircraft Geophysica and HALO. It is planned to install GLORIA on board a stratospheric balloon in order to perform 
long-term measurements at altitudes up to $40 \mathrm{~km}$ for several weeks.

It is common practice for balloon-borne FTS instruments to establish onboard two-point calibration procedures using deep space as one reference point and a temperature stabilized blackbody (e.g., Té et al., 2002; Friedl-Vallon et al., 2004). That approach ensures the consistency of the measurements over a long period of time in a variable environment with changing detector sensitivity due to temperature alteration of the instrument. As the environmental conditions at the flight altitude $(35-38 \mathrm{~km})$ are very different from those on board a research aircraft, a new concept for the in-flight calibration system had to be developed. Especially the limitation of electrical power was an important factor in the design of the new large-area blackbody calibration source.

\section{The GLORIA instrument}

GLORIA is a joint project of Research Center Juelich and the Karlsruhe Institute of Technology, Germany. GLORIA is designed as an imaging FTS operating in the thermal infrared spectral region from 770 to $1400 \mathrm{~cm}^{-1}$ (Friedl-Vallon et al., 2014). The spectral resolution is adjusted to two different measuring modes: $1.25 \mathrm{~cm}^{-1}$ for the dynamics mode and $0.1 \mathrm{~cm}^{-1}$ for the chemistry mode, respectively. A twolens aspherical telescope with an aperture of approximately $36 \mathrm{~mm}$ and a vertical and horizontal field of view (FOV) of $4.07^{\circ} \times 4.07^{\circ}$ is used to image the atmosphere. The radiation coming from the atmosphere is directly projected onto a large two-dimensional photovoltaic MCT detector array mounted in a dewar with an integrated Stirling cooler. GLORIA makes novel information on small-scale atmospheric dynamics available, e.g., STE, the stratosphere-troposphere exchange and other important phenomena (Riese et al., 2014; Ungermann et al., 2011; Ungermann et al., 2015).

In order to study long-term phenomena in the stratosphere for up to 2 weeks, GLORIA shall be installed into a gondola of a stratospheric balloon. A schematic of the balloon instrument is shown in Fig. 1. The GLORIA balloon instrument utilizes a rotatable mirror for line-of-sight stabilization during measurement. This mirror is also used to adjust the line-of-sight to the blackbody calibration source and to view deep space.

\section{Calibration concept and requirements}

In order to retrieve temperature and trace gas concentrations in the atmosphere, the measured detector signals need to be converted into atmospheric infrared radiance spectra with very small uncertainties. Assuming that the measurement system has a linear response, the required high accuracy can be achieved by a two point calibration in the range of the observed atmospheric radiance (Kleinert et al., 2014). Deep space as an ideal blackbody with a very uniform tem-

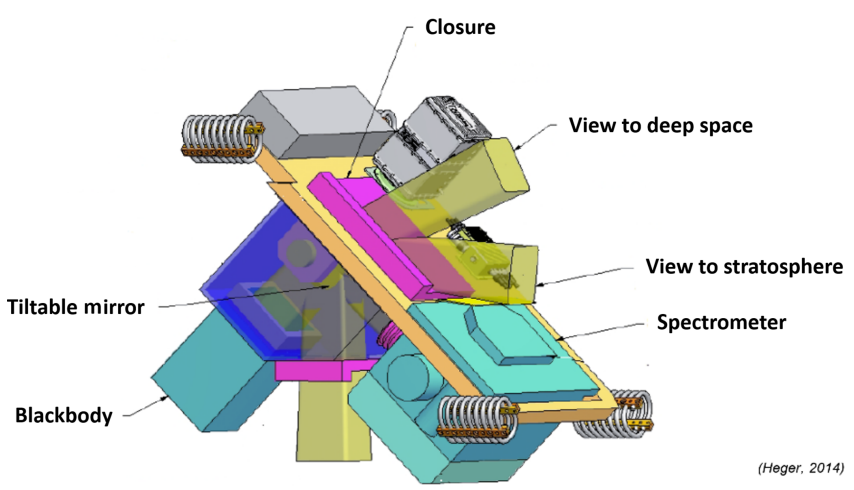

Figure 1. Schematic of the GLORIA balloon instrument.

Table 1. Requirements for the large-area blackbody calibration source

\begin{tabular}{lr}
\hline Optical surface & $125 \mathrm{~mm} \times 125 \mathrm{~mm}$ \\
Temperature range & -30 to $-35^{\circ} \mathrm{C}$ \\
Temperature uncertainty & $<0.1 \mathrm{~K}$ \\
Effective emissivity $(7-13 \mu \mathrm{m})$ & $>0.99$ \\
Spatial temperature uniformity & $<0.15 \mathrm{~K}$ \\
Short-term temperature stability & $<25 \mathrm{mK} \mathrm{min}^{-1}$ \\
\hline
\end{tabular}

perature of $2.7 \mathrm{~K}$ is a perfect calibration source for the detector. By looking at different sectors of the sky, the influence of star light can be subtracted. As second calibration source a large-area blackbody at a temperature of about $240 \mathrm{~K}$ with high temperature homogeneity of better than $0.15 \mathrm{~K}$ shall be used.

As the uncertainties in spectral radiance of the blackbody calibration source influence the uncertainties in the measured atmospheric radiances, radiometric calibration of the instrument with an uncertainty of less than $1 \%$ is necessary (Olschewski et al., 2012). This requires a very high emissivity of greater than 0.99 and very precise temperature measurement with a temperature uncertainty of less than $0.1 \mathrm{~K}$. For the technical realization of the radiometric accuracy, the large-area blackbody calibration source has to fulfill the requirements listed in Table 1.

\section{Design of the GLORIA balloon blackbody}

The GLORIA in-flight calibration system uses a highprecision blackbody radiation source, which is operated at a temperature of about $240 \mathrm{~K}$. The optical surface of this balloon blackbody (BBB) consists of a wire-eroded aluminum plate with an array of 225 small pyramids, which are varnished with NEXTEL-Velvet Coating (see Fig. 2). Integrated in a housing with outer dimensions of $140 \mathrm{~mm} \times 140 \mathrm{~mm} \times 200 \mathrm{~mm}$, the optical surface has an effective emissivity of $\epsilon>0.997$. In order to verify the thermal uniformity, ten thermally cycled and calibrated platinum re- 


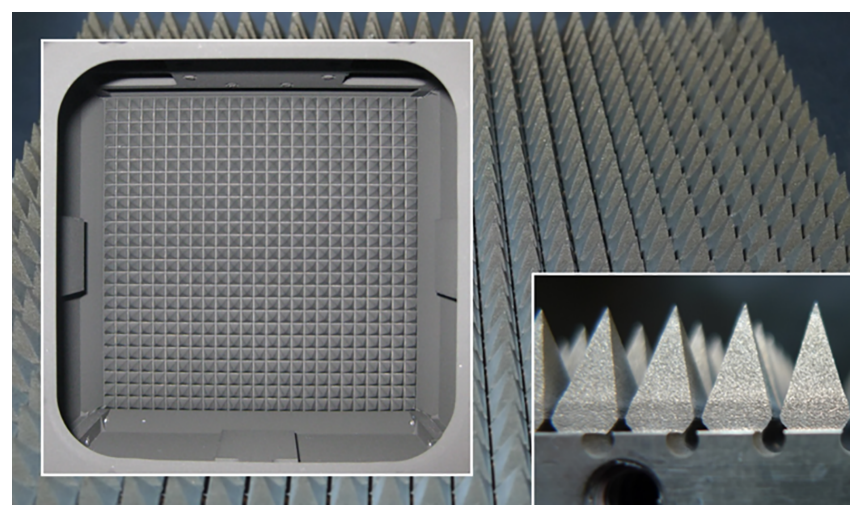

Figure 2. Optical surface of large-area blackbody with wire-eroded pyramid array. Size of a single pyramid: base $=5 \mathrm{~mm} \times 5 \mathrm{~mm}$; height $=9 \mathrm{~mm}$.

sistance thermometers (PRTs) are installed in the aluminum plate.

For thermal decoupling of the blackbody calibration source from the GLORIA balloon instrument, Glass-Fiber Reinforced Plastic (GFRP) parts are used. In order to reduce the adverse influence of the thermal environment, the BBB is covered with polystyrene foam sheets (see Fig. 3).

For temperature stabilization of the airborne GLORIA Blackbodies (GBBs) thermo-electric coolers (TECs) are used (cf. Olschewski et al., 2013). This concept is not feasible for the balloon-borne instrument because the power consumption is too high and there is not sufficient air for cooling the heat exchangers at flight altitude. Therefore, a different design concept is realized. The phase change of a eutectic material is used to stabilize the temperature of the optical surface at about $-32^{\circ} \mathrm{C}$.

Six commercial cooling pads from Va-Q-tec are used for thermal stabilization (https://www.va-q-tec.com/de/ produkte/kaelte-und-waermespeicher/va-q-accu-32g.html, last access: 10 August 2018). Table 2 gives the properties of the PCM (phase change material) cooling pads. Two cooling pads are used for temperature control of the optical surface while one each will control the temperature of the four walls of the housing.

In order to get the PCM into the solid state, pre-cooling with a chiller or with liquid nitrogen is needed. Therefore, the PCM cooling pads are equipped with heat exchangers made of aluminum shown in Fig. $3 b$.

\section{Lab tests and test in a thermal vacuum chamber}

In order to study the thermal behavior of the BBB, thermal tests were performed in the lab and in the thermal vacuum chamber of Research Centre Juelich. It was the goal of these tests to measure the progression of the phase change and to estimate the possible operating time on a balloon mission in the stratosphere. Figure 4 a shows the thermal behavior dur-
Table 2. Properties of the PCM cooling pads "va-Q-accu-32G".

\begin{tabular}{lr}
\hline Freezing/melting point & $-32^{\circ} \mathrm{C}$ \\
Heat capacity (solid) & $2.95 \mathrm{~kJ} \mathrm{~kg}^{-1} \mathrm{~K}^{-1}$ \\
Latent heat & $243 \mathrm{~kJ} \mathrm{~kg}^{-1}$ \\
Dimensions & $165 \mathrm{~mm} \times 88 \mathrm{~mm} \times 20 \mathrm{~mm}$ \\
PCM mass & $0.28 \mathrm{~kg}$ \\
\hline
\end{tabular}

ing a lab test while the aperture was closed with a polystyrene foam sheet. The pre-cooling of the PCM cooling pads was achieved by storing the complete device in a cooling box for $12 \mathrm{~h}$. The progression of the phase change lasted $7 \mathrm{~h}$ with a very small temperature change of $35 \mathrm{mKh}^{-1}$. In the thermal vacuum chamber the most realistic condition of a balloon flight was simulated. The chamber pressure was set to $10 \mathrm{hPa}$ and the temperature to $-22^{\circ} \mathrm{C}$, respectively. The complete temperature evolution over time is shown in Fig. 4b. Unfortunately, the test had to be discontinued after $320 \mathrm{~h}$ for organizational reasons. At the beginning of the test, the mean BBB temperature was about $-33.5^{\circ} \mathrm{C}$. The phase change started nearly a week later and was still ongoing when the test ended. As the temperature trend in the solid state was very small, calibrating the GLORIA instrument before the onset of the phase change during a balloon flight will also be possible.

\section{Radiometric characterization}

The radiometric characterization of the large-area blackbody was performed inside the Reduced Background Calibration Facility (RBCF) (Hollandt et al., 2003/2004; Monte et al., 2009) of the Physikalisch-Technische Bundesanstalt (PTB) as shown in Fig. 5. The pressure inside the RBCF was set to $10 \mathrm{hPa}$ corresponding to the ambient pressure expected in the stratosphere. The heat exchangers of the blackbody calibration source were connected to an external chiller. By adjusting the temperature of the coolant, the PCM elements were taken to the solid state first and then the chiller thermostat was set slightly above the melting point. Due to its large optical surface, the blackbody faces a thermally nonuniform environment inside the RBCF with temperatures in the range between -120 and $23^{\circ} \mathrm{C}$. The cooled optical pathway suppressing the background radiation from the wall and surrounding the field of view of the VIRST along its line of sight is a sequence of cooled apertures and tubes. This aperture system (beamline) extends into the source chamber and has there an outer diameter of $40 \mathrm{~mm}$. As the opening of the balloon blackbody is $100 \mathrm{~mm}$ by $100 \mathrm{~mm}$, only a part of this aperture sees the cooled beamline $\left(-120^{\circ} \mathrm{C}\right)$ while the remaining aperture of the blackbody receives radiation from the inner walls of the source chamber, which are at room temperature. Therefore, the radiation exchange with the environment through the aperture is neither identical to the operating conditions in the stratosphere nor to the measurement 

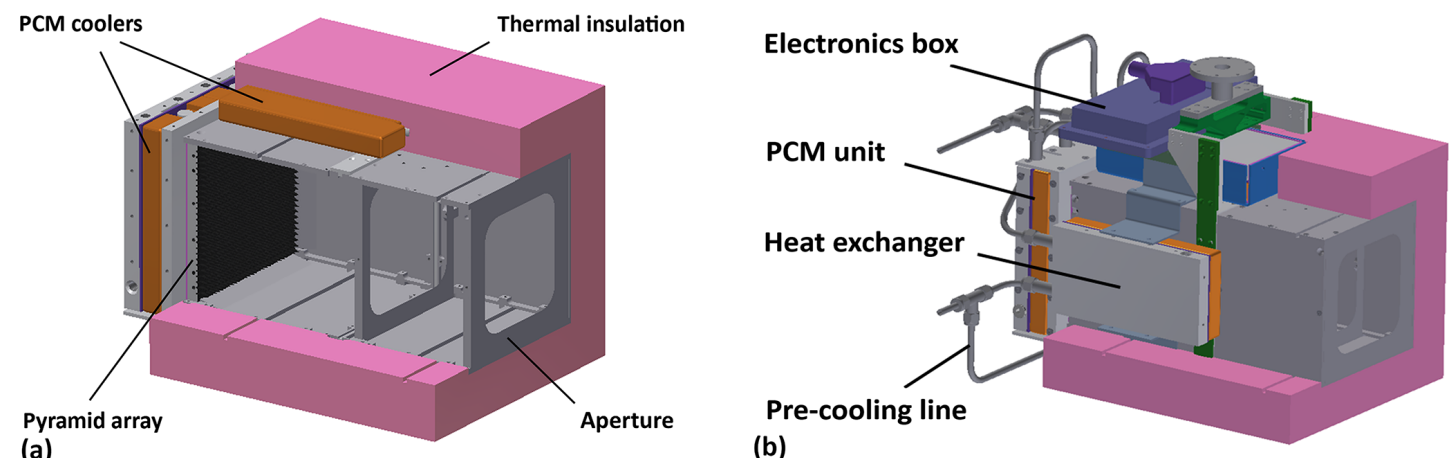

Figure 3. Design of balloon blackbody (a) with electronics and heat exchangers for pre-cooling (b).
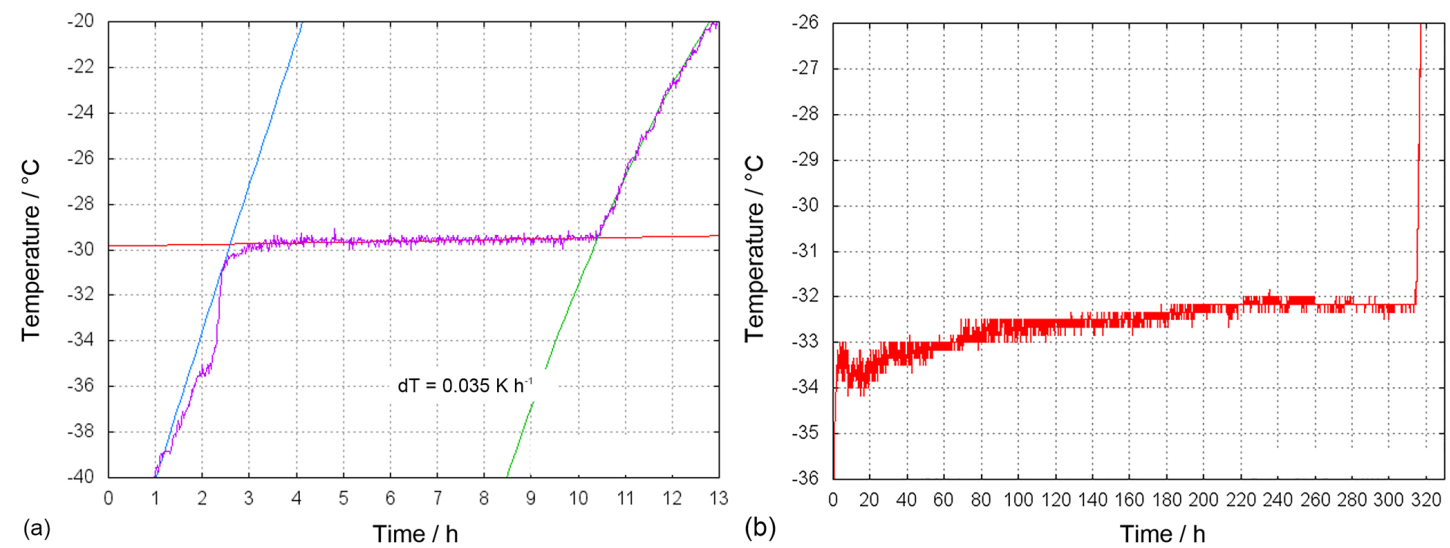

Figure 4. Lab test of the melting plateau at an ambient pressure of about $1013 \mathrm{hPa}$ and an ambient temperature of about $23^{\circ} \mathrm{C}(\mathbf{a})$; and a thermal-vacuum test of the $\mathrm{BBB}$ at ambient pressure of $10 \mathrm{hPa}$ and ambient temperature of about $-22^{\circ} \mathrm{C}(\mathbf{b})$.

setup in the thermal-vacuum chamber. In spite of this drawback, a phase change time (melting-plateau) of more than $8 \mathrm{~h}$ could be reached. During this phase change period the radiance temperature and its lateral distribution was measured.

The change of radiance temperature and of contact temperature over time is shown in Fig. 6 together with the set temperature of the external chiller for thermalizing the heat exchangers. The collinearity of radiance temperature and contact temperature is obvious. The slightly higher radiance temperature results from the thermal gradient between sensor and emitting surface due to the thermal conductivities of the aluminium and the coating and the non-ideal emissivity of the BBB. Due to the latter, a part of the radiation from the surrounding ( 1 - emissivity) contributes to the apparent radiance temperature and leads to higher apparent temperatures when the BBB is operated below room temperature.

Figure 7 demonstrates the very high spatial uniformity of the radiance temperature of better than $100 \mathrm{mK}$ (peak-topeak) over the used area of the aperture of the blackbody. The sampling of the radiating surface of the blackbody was performed by the calibrated broad band radiation thermometer VIRST $(8-14 \mu \mathrm{m})$ (Gutschwager et al., 2008). These results show the suitability of the large-area blackbody BBB for the radiometric traceability of balloon-borne imaging spectrometers as GLORIA.

The blackbody should not be considered as reference blackbody operating at a fixed temperature given by the melting plateau of the PCM material. Rather, the PCM material should be considered as a reservoir for latent heat only, enabling the operation of the blackbody with very low energy consumption. By using well characterized PTR sensors in the backplane which are absolutely calibrated with low uncertainties, the momentary temperature of the backplane can be determined (cf. Fig. 6) and the corresponding radiance temperature is given as well by the characterization with VIRST. Additional radiometric characterizations of the lateral distribution of the radiance temperature in the liquid and frozen state revealed also a very good uniformity. This would permit the use of the blackbody even under these conditions.

\section{Summary and conclusions}

The Institute for Atmospheric and Environmental Research at the University of Wuppertal developed a large-area calibration source based on phase change material for deployment on board stratospheric balloons. The newly designed 

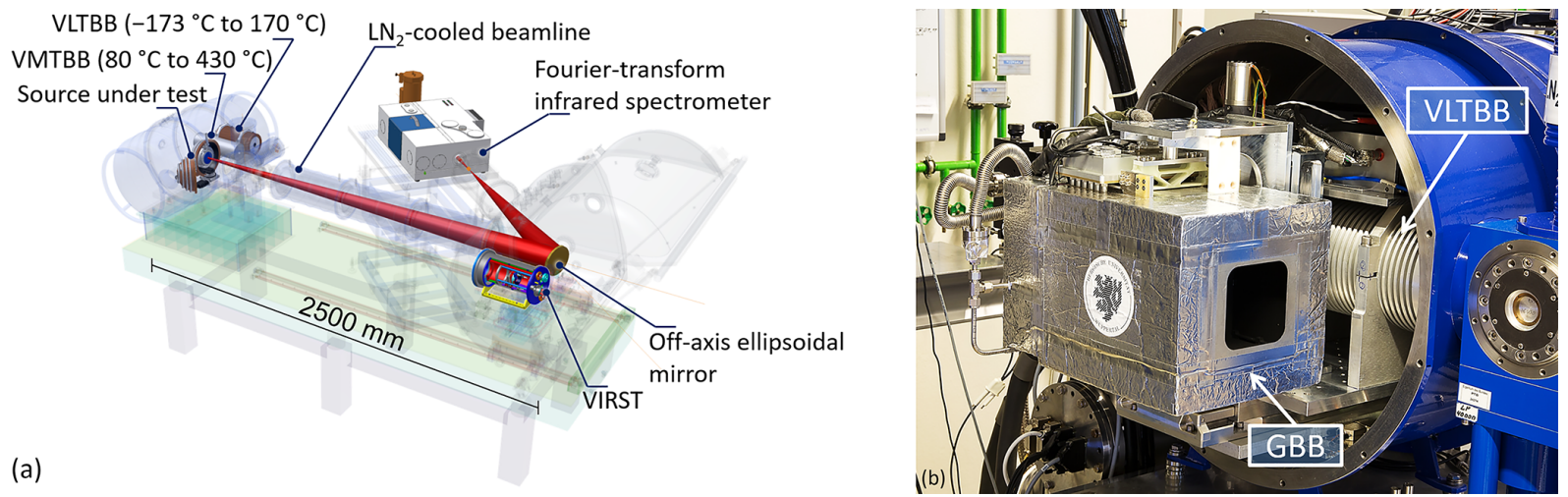

Figure 5. (a) The Reduced Background Calibration Facility (RBCF) at PTB and (b) the large-area balloon blackbody inside the source chamber of the RBCF.

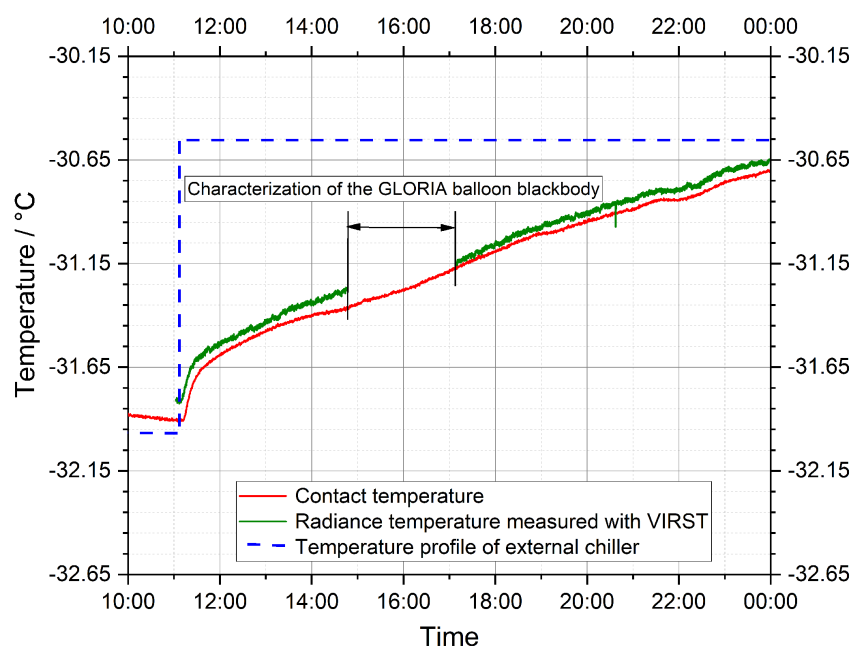

Figure 6. Change of radiance temperature and of contact temperature in the backplane of the GLORIA balloon blackbody over time during phase change in PCM cooling pads.

blackbody can be used for precise in-flight calibration of hyperspectral cameras which are assigned for remote sensing of the atmosphere. The use of phase change material enables a long-lasting temperature stability without any power consumption, which is essential for long duration balloon flights. The radiometric characterization at PTB showed that the requirement regarding the uncertainty in radiance temperature and its uniformity across the aperture below $100 \mathrm{mK}$ can be reached. So atmospheric measurements employing this blackbody will become traceable to the International Temperature Scale (ITS-90) with low uncertainties.

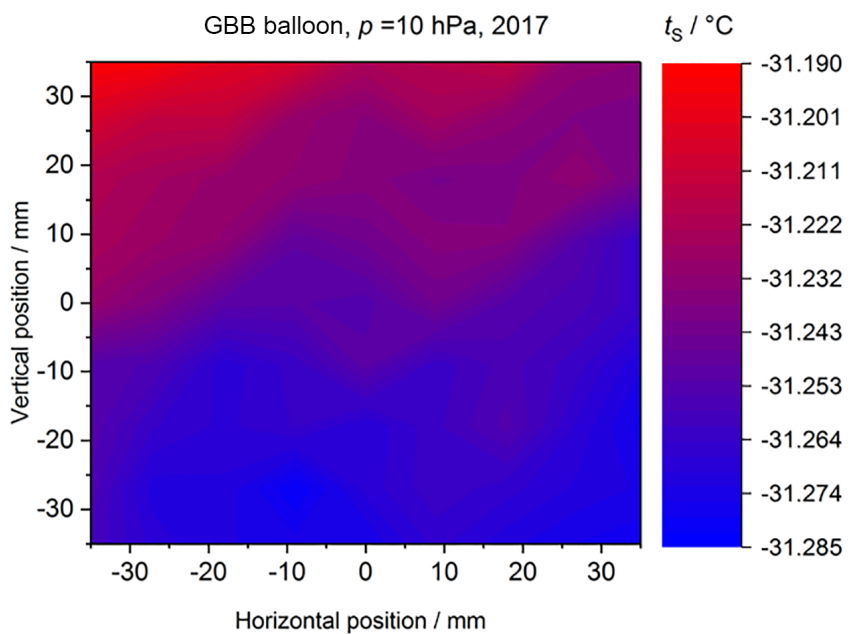

Figure 7. Lateral radiance temperature distribution of the largearea blackbody, recorded during phase change, featuring a nonuniformity of less than $100 \mathrm{mK}$ (peak-to-peak).

Data availability. Data are presented throughout the text. Test results can be found directly in Figs. 4, 6, and 7 .

Competing interests. The authors declare that they have no conflict of interest.

Acknowledgements. Part of this work has been supported by the European Metrology Research Programme (EMRP) within the joint research project Metrology for Earth Observation and Climate (MetEOC2). The EMRP is jointly funded by the EMRP of the participating countries within EURAMET and the EU.

Edited by: Alyn Lambert

Reviewed by: two anonymous referees 


\section{References}

Friedl-Vallon, F.: Five Years of GLORIA Flights: Results and Lessons Learnt, in: Light, Energy and the Environment, p. FM3E.3, Opt. Soc. Am., https://doi.org/10.1364/FTS.2016.FM3E.3, 2016.

Friedl-Vallon, F., Maucher, G., Seefeldner, M., Trieschmann, O., Kleinert, A., Lengel, A., Keim, C., Oelhaf, H., and Fischer, H.: Design and characterization of the balloonborne Michelson Interferometer for Passive Atmospheric Sounding (MIPAS-B2), Appl. Opt., 43, 3335-3355, https://doi.org/10.1364/AO.43.003335, 2004.

Friedl-Vallon, F., Riese, M., Maucher, G., Lengel, A., Hase, F., Preusse, P., and Spang, R.: Instrument concept and preliminary performance analysis of GLORIA, Adv. Space Res., 37, 22872291, https://doi.org/10.1016/j.asr.2005.07.075, 2006.

Friedl-Vallon, F., Gulde, T., Hase, F., Kleinert, A., Kulessa, T., Maucher, G., Neubert, T., Olschewski, F., Piesch, C., Preusse, P., Rongen, H., Sartorius, C., Schneider, H., Schönfeld, A., Tan, V., Bayer, N., Blank, J., Dapp, R., Ebersoldt, A., Fischer, H., Graf, F., Guggenmoser, T., Höpfner, M., Kaufmann, M., Kretschmer, E., Latzko, T., Nordmeyer, H., Oelhaf, H., Orphal, J., Riese, M., Schardt, G., Schillings, J., Sha, M. K., Suminska-Ebersoldt, O., and Ungermann, J.: Instrument concept of the imaging Fourier transform spectrometer GLORIA, Atmos. Meas. Tech., 7, 35653577, https://doi.org/10.5194/amt-7-3565-2014, 2014.

Gutschwager, B., Hollandt, J., Jankowski, T., and Gaertner, R.: A Vacuum Infrared Standard Radiation Thermometer at the PTB, Int. J. Thermophys., 29, 330-340, https://doi.org/10.1007/s10765-007-0349-x, 2008.

Hollandt, J., Friedrich, R., Gutschwager, B., Taubert, D., and Hartmann, J.: High-accuracy Radiation Thermometry at the National Metrology Institute of Germany - the PTB, High Temperatures - High Pressures, 35/36, 379-415, 2003/2004.

Johansson, S., Friedl-Vallon, F., Höpfner, M., Ungermann, J., Vogel, B., Grooß, J., Müller, R., Diekmann, C., Schröter, J., Ruhnke, R., Orphal, J., and the GLORIA Team: 2-d chemical sampling of a tropopause fold over the Mediterranean: Observations by the IR limb-imager GLORIA and calculations by chemistry-transport models, in: Geophysical Research Abstracts Vol. 19, EGU201712140, 2017.

Kaufmann, M., Blank, J., Guggenmoser, T., Ungermann, J., Engel, A., Ern, M., Friedl-Vallon, F., Gerber, D., Grooß, J. U., Guenther, G., Höpfner, M., Kleinert, A., Kretschmer, E., Latzko, T., Maucher, G., Neubert, T., Nordmeyer, H., Oelhaf, H., Olschewski, F., Orphal, J., Preusse, P., Schlager, H., Schneider, H., Schuettemeyer, D., Stroh, F., Suminska-Ebersoldt, O., Vogel, B., M. Volk, C., Woiwode, W., and Riese, M.: Retrieval of threedimensional small-scale structures in upper-tropospheric/lowerstratospheric composition as measured by GLORIA, Atmos. Meas. Tech., 8, 81-95, https://doi.org/10.5194/amt-8-81-2015, 2015.

Kleinert, A., Friedl-Vallon, F., Guggenmoser, T., Höpfner, M., Neubert, T., Ribalda, R., Sha, M. K., Ungermann, J., Blank, J., Ebersoldt, A., Kretschmer, E., Latzko, T., Oelhaf, H., Olschewski, F., and Preusse, P.: Level 0 to 1 processing of the imaging Fourier transform spectrometer GLORIA: generation of radiometrically and spectrally calibrated spectra, Atmos. Meas. Tech., 7, 41674184, https://doi.org/10.5194/amt-7-4167-2014, 2014.
Krisch, I., Preusse, P., Ungermann, J., Dörnbrack, A., Eckermann, S. D., Ern, M., Friedl-Vallon, F., Kaufmann, M., Oelhaf, H., Rapp, M., Strube, C., and Riese, M.: First tomographic observations of gravity waves by the infrared limb imager GLORIA, Atmos. Chem. Phys., 17, 14937-14953, https://doi.org/10.5194/acp-17-14937-2017, 2017.

Monte, C., Gutschwager, B., and Hollandt, J.: The Reduced Background Calibration Facility for Detectors and Radiators at the Physikalisch-Technische Bundesanstalt, in: Proc. of SPIE Vol. 7474 Sensors, Systems, and Next-Generation Satellites XIII, 747414, https://doi.org/10.1117/12.830454, 2009.

Olschewski, F., Rolf, C., Steffens, P., Kleinert, A., Piesch, C., Ebersoldt, A., Monte, C., Gutschwager, B., J., H., Preusse, P., Friedl-Vallon, F., and Koppmann, R.: In-flight blackbody calibration sources for the GLORIA interferometer, in: Proc. SPIE 8511, Infrared Remote Sensing and Instrumentation XX, 85110I, https://doi.org/10.1117/12.928194, 2012.

Olschewski, F., Ebersoldt, A., Friedl-Vallon, F., Gutschwager, B., Hollandt, J., Kleinert, A., Monte, C., Piesch, C., Preusse, P., Rolf, C., Steffens, P., and Koppmann, R.: The in-flight blackbody calibration system for the GLORIA interferometer on board an airborne research platform, Atmos. Meas. Tech., 6, 3067-3082, https://doi.org/10.5194/amt-6-3067-2013, 2013.

Riese, M., Oelhaf, H., Preusse, P., Blank, J., Ern, M., Friedl-Vallon, F., Fischer, H., Guggenmoser, T., Höpfner, M., Hoor, P., Kaufmann, M., Orphal, J., Plöger, F., Spang, R., Suminska-Ebersoldt, O., Ungermann, J., Vogel, B., and Woiwode, W.: Gimballed Limb Observer for Radiance Imaging of the Atmosphere (GLORIA) scientific objectives, Atmos. Meas. Tech., 7, 1915-1928, https://doi.org/10.5194/amt-7-1915-2014, 2014.

Té, Y., Jeseck, P., Camy-Peyret, C., Payan, S., Perron, G., and Aubertin, G.: Balloonborne calibrated spectroradiometer for atmospheric nadir sounding, Appl. Optics, 41, 6431-6441, https://doi.org/10.1364/AO.41.006431, 2002.

Ungermann, J., Blank, J., Lotz, J., Leppkes, K., Hoffmann, L., Guggenmoser, T., Kaufmann, M., Preusse, P., Naumann, U., and Riese, M.: A 3-D tomographic retrieval approach with advection compensation for the air-borne limb-imager GLORIA, Atmos. Meas. Tech., 4, 2509-2529, https://doi.org/10.5194/amt-4-25092011, 2011.

Ungermann, J., Blank, J., Dick, M., Ebersoldt, A., Friedl-Vallon, F., Giez, A., Guggenmoser, T., Höpfner, M., Jurkat, T., Kaufmann, M., Kaufmann, S., Kleinert, A., Krämer, M., Latzko, T., Oelhaf, H., Olchewski, F., Preusse, P., Rolf, C., Schillings, J., Suminska-Ebersoldt, O., Tan, V., Thomas, N., Voigt, C., Zahn, A., Zöger, M., and Riese, M.: Level 2 processing for the imaging Fourier transform spectrometer GLORIA: derivation and validation of temperature and trace gas volume mixing ratios from calibrated dynamics mode spectra, Atmos. Meas. Tech., 8, 24732489, https://doi.org/10.5194/amt-8-2473-2015, 2015. 